\title{
LOS EFECTOS DE LA CENSURA FRANQUISTA: LA JUERGA [1957, 1961], UNA NOVELA INÉDITA DE ÁNGEL MARÍA DE LERA (1912-1984)
}

\author{
DIE AUSWIRKUNGEN DER ZENSUR UNTER FRANCO: \\ LA JUERGA [1957, 1961], EIN UNVERÖFFENTLICHER \\ ROMAN VON ÁNGEL MARÍA DE LERA (1912-1984)
}

María del Mar Jorge de SANDE ${ }^{\mathrm{I}}$ Friedrich-Alexander Universität Erlangen-Nürnberg mjorge41@alumno.uned.es

Fecha de recepción: 20-09-2018

Fecha de aceptación: 15-03-2019

\section{RESUMEN}

Ángel María de Lera (1912-1984), autor de éxito en las décadas del sesenta y setenta del pasado siglo, es en la actualidad un escritor apenas recordado y muy poco conocido. Y ello a pesar de ocupar un importante lugar en la Historia de la Literatura española gracias a Las últimas banderas (Premio Planeta 1967), una de las primeras novelas publicadas en España que trata sobre la Guerra Civil desde la perspectiva de un vencido. Muy poco conocidas son también las muchas dificultades que hubo de enfrentar para publicar algunas de sus obras a consecuencia de la censura.

Con este artículo nos proponemos rescatar del olvido la novela La juerga [1957, 1961], sepultada en los archivos de la represión franquista durante casi sesenta años. Su análisis desde el punto de vista literario pondrá de manifiesto cómo el hecho de que esta novela quedara inédita constituye una grave mutilación en el conjunto de la obra de Lera; con el

\footnotetext{
${ }^{1}$ María del Mar Jorge de Sande pertenece al Programa de Filología de la EIDUNED y el presente trabajo se enmarca dentro de la investigación de su tesis en dicho Programa.
} 
estudio de su expediente de censura esperamos arrojar luz sobre las posibles causas por las que a Lera le resultó imposible publicarla, al tiempo que confiamos en hacer una pequeña aportación a la reconstrucción del complejo entramado de la institución censoria.

PAlabras Clave: Ángel María de Lera; La juerga; censura franquista.

\section{ZUSAMMENFASSUNG}

Kaum jemand erinnert sich heute noch an Ángel María de Lera (1912-1984), einen Erfolgsautor in den 60er und 70er Jahren des letzten Jahrhunderts, kaum jemand kennt ihn überhaupt. Und dennoch hat er aufgrund seines Romans Las últimas banderas (Premio Planeta 1967) einen bedeutenden Platz in der Geschichte der spanischen Literatur inne, war es doch immerhin einer der ersten in Spanien veröffentlichten Romane, in denen es um den Spanischen Bürgerkrieg aus dem Blickwinkel eines Besiegten ging. Wenig sind auch die vielen Schwierigkeiten bekannt, denen sich Lera infolge der damals herrschenden Zensur bei der Veröffentlichung einiger seiner Werke ausgesetzt sah.

Mit diesem Artikel soll der Roman La Juerga [1957, 1961] vor dem Vergessen bewahrt werden. Fast 60 Jahre lang war er begraben in den Archiven, in denen die Zeugnisse der franquistischen Unterdrückung aufbewahrt werden. Die literarische Analyse von La Juerga zeigt klar und deutlich, dass, diesen Roman dem Publikum weiterhin vorzuenthalten, dem Gesamtwerk von Lera schweren Schaden zufügen würde. Der genaue Blick in die Unterlagen der Zensurbehörde wird Licht werfen auf die möglichen Gründe, die dazu geführt haben, dass dieser Roman nicht veröffentlicht werden konnte, und so sicherlich einen kleinen Beitrag dabei leisten, die komplexe Struktur der institutionalisierten Zensur zu rekonstruieren.

SCHLÜSSELwÖRTER: Ángel María de Lera; La juerga; Zensur in der Franco-Zeit.

\section{ARTíCULO}

A la memoria de Pilar Calero Medina

Ángel María de Lera² (Baides, 1912-Madrid, 1984) fue un autor de éxito en los años sesenta y setenta del pasado siglo, aunque hoy haya caído en el más absoluto de los olvidos.

\footnotetext{
${ }^{2}$ Existen dos biografías de Ángel María de Lera, ambas escritas en vida del autor: RODRÍGUEZ DE LAS HERAS, Antonio (1971), Angel M. ${ }^{a}$ de Lera, Madrid, Epesa y HERNÁNDEZ, Ramón (1981), Angel María de Lera, Madrid, Ministerio de Cultura. Una inagotable fuente de información la constituye también el Archivo de Ángel María de Lera, adquirido por la Biblioteca Nacional de España (BNE) a sus herederos en 1996. Contiene un extenso epistolario, así como también numerosos documentos de gran interés (BNE, Arch. AML/1-38. Período que abarca: 1935-1984). (En proceso de descripción, el Archivo de Ángel María de Lera no se hallaba todavía
} 
Combatiente en las filas republicanas, sufrió, tras la guerra, casi ocho años de prisión, razón que explica su tardía incorporación al mundo de las letras.

Publica Los olvidados, su ópera prima, en 1957, momento de eclosión de la novela social. Los olvidados presenta notables coincidencias, tanto temáticas como formales, con las obras de los entonces jóvenes narradores. De ahí que parte de la crítica haya adscrito a nuestro autor a la llamada Generación del 50. Sin embargo, quienes han estudiado su obra de forma más profunda insisten en el carácter transicional de su figura, a caballo entre dos generaciones literarias, y en su profunda independencia. ${ }^{3}$

Los olvidados pasa completamente desapercibida tanto para el público como para la crítica. No obstante, tan solo un año después de su publicación, en 1958, Lera sorprenderá a ambos con una obra de tema taurino que concitará los unánimes elogios tanto de la crítica española como extranjera, Los clarines del miedo. Hemos perdido el sol (1963) y Tierra para morir (1964), novelas en las que analiza el fenómeno de la emigración, constituyen nuevos hitos en su trayectoria. Pero si Ángel María de Lera ocupa un merecido lugar en las historias de la literatura española es gracias a Las últimas banderas (1967), una de las primeras novelas que en España trata el tema de la Guerra Civil desde la perspectiva de un vencido.

Autor prolífico y versátil, a lo largo de su vida publicará un total de dieciséis novelas, tres libros de viajes, obras de carácter ensayístico, la biografía del líder anarcosindicalista Ángel Pestaña e innumerables artículos periodísticos. Ángel María de Lera destaca, además, por su labor en defensa de los derechos de los escritores, labor que le llevará a la creación de la Mutualidad de Escritores de Libros en 1970 y de la Asociación Colegial de Escritores de España en 1976.

Las novelas de Lera disfrutaron tanto del favor de la crítica como del público. Y así, en 1966 Escolar Bareño sostenía: “Cualquiera que sea el juicio de los críticos, nacionales o extranjeros, respecto a las novelas de este autor, no se puede hablar de novela española contemporánea sin mencionar su nombre y su producción". ${ }^{4}$ Para García de Nora Lera era una "revelación tardía, pero en extremo significativa e importante". ${ }^{5}$ La trayectoria de Lera era, en opinión de Marra-López, "una de las más curiosas e interesantes de nuestra literatura actual". ${ }^{6}$

Su labor fue recompensada con la concesión de premios como el “Álvarez Quintero", de la RAE, y el "Benito Pérez Galdós", de la Casa Colón de Las Palmas de Gran Cana-

\footnotetext{
abierto al público en mis primeras visitas a la BNE. No obstante, me fue permitida la consulta de los documentos que necesitaba para mi investigación. Agradezco la profesionalidad y el amable trato de las personas que me atendieron, en particular de la Jefa de la Sección de Manuscritos e Incunables, María José Rucio Zamorano).

${ }^{3}$ LISTERMAN, Mary Sue (1982), Angel María de Lera, Boston, Twayne Publishers, "Preface" (no figura página); LEEDER, Ellen Lismore (1978), El desarraigo en las novelas de Angel María de Lera, Miami, Ediciones Universal, p. 17.

${ }^{4}$ ESCOLAR BAREÑO, Luis (1966), Prólogo a Novelas, de Ángel María de Lera, Madrid, Aguilar, p. VII.

5 GARCÍA DE NORA, Eugenio (1970²), La novela española contemporánea (1939-1967), Tomo III, Madrid, Gredos, p. 181.

${ }^{6}$ MARRA-LÓPEZ, José Ramón (1964), “Una novela de interés nacional”, Ínsula, 207, p. 5.
} 
ria, por Tierra para morir; el Planeta, por Las últimas banderas; o el "Ateneo de Sevilla" y "Fastenrath", de la RAE también, por Se vende un hombre (1973).

Pese a una trayectoria tan dilatada y tan jalonada de éxitos, lo cierto es que la bibliografía específica existente sobre la figura de Ángel María de Lera sigue siendo escasa. ${ }^{7}$ Por otro lado, sorprende la ausencia de estudios que aborden el análisis de la producción leriana desde la perspectiva de la censura, sobre todo si tenemos en cuenta que nuestro autor escribe la mayor parte de su obra condicionado por este ineludible factor. ${ }^{8}$

El objetivo que perseguimos con nuestro artículo es, pues, doble: en primer lugar, arrojar nueva luz sobre la bibliografía leriana con un trabajo que, al rescatar del olvido la novela inédita La juerga [1957, 1961], ofrece por vez primera una visión completa de la producción novelística del autor; en segundo lugar, contribuir al estudio del ejercicio de la censura en España, mediante el análisis del expediente de censura de La juerga, sepultado en los archivos de la represión franquista durante más de sesenta años.

\section{LA JUERGA [1957, 1961] EN LA PRIMERA ETAPA DE LA PRODUCCIÓN NOVELÍSTICA DE ÁNGEL MARÍA DE LERA}

Ángel María de Lera inicia su andadura literaria a los cuarenta y cinco años con la publicación en 1957 de Los olvidados. Según Rodríguez de las Heras ${ }^{9}$, primer biógrafo y amigo personal de nuestro autor, ese mismo año Lera escribe La juerga, también titulada Bronce. En 1958 aparece Los clarines del miedo, que el escritor había presentado al premio Nadal en $1956 .{ }^{10}$

\footnotetext{
7 Además de las biografías y de los documentos contenidos en el Archivo de Ángel María de Lera, mencionados en la nota 2, existen varios prólogos y trabajos monográficos sobre la figura y la obra de nuestro autor. Los prólogos, ordenados cronológicamente, son: el ya citado de Luis Escolar Bareño y los de HATTON, Robert W. (1971), Los clarines del miedo, Waltham, Massachusetts, Ginn and Company; HERNÁNDEZ, Ramón (1980), Prólogo a Los clarines del miedo, Madrid, Espasa-Calpe S. A.; CASTRO DÍEZ, Asunción (2004), Los olvidados, Madrid, Castalia. Los trabajos monográficos, tesinas y tesis doctorales en su origen, y, por lo tanto, inéditos algunos de ellos, fueron realizados por investigadores estadounidenses: THOMAS, Owen Durant (1972), La vida y obras de Angel María de Lera (University of Illinois), Michigan, University Microfilms International; WEHR, Gayle C. (1974), La novelística de Angel María de Lera (The Florida State University), Michigan, Xerox University Microfilms; THOMAS, Owen Durant (1977), Angel María de Lera: the Man and his Novel (New York University), Michigan, University Microfilms International y los mencionados trabajos de Ellen Lismore Leeder y Mary Sue Listerman.

${ }^{8}$ Existe un trabajo inédito, "Análisis de tres novelas de Ángel María de Lera, que tienen como telón de fondo la Guerra Civil, a la luz de sus expedientes de censura: Las últimas banderas (1967), Se vende un hombre (1973) y Los que perdimos (1974)", realizado por la autora de este artículo. Fue dirigido por la Dra. Dña. Lucía Montejo Gurruchaga, profesora de literatura española de la UNED, a lo largo del curso académico 2010-2011.

9 RODRÍGUEZ DE LAS HERAS, Antonio, op. cit., p. 95. Mary Sue Listerman también recoge este dato, años después, en su libro (LISTERMAN, Mary Sue, op. cit., "Chronology" (no figura página)).

${ }^{10}$ RODRÍGUEZ DE LAS HERAS, Antonio, op. cit., p. 66 y LISTERMAN, Mary Sue, op. cit., "Chronology” (no figura página).
} 
De La juerga existen tres originales: uno de ellos se halla en el Archivo General de la Administración (AGA), en Alcalá de Henares ${ }^{11}$; otro, en poder de los herederos de Lera ${ }^{12}$; el tercero se encuentra en la BNE. ${ }^{13}$ Ninguno de ellos aparece fechado, por lo que resulta imposible contrastar la veracidad de la fecha de composición de la novela, aportada como fuente primaria únicamente por Rodríguez de las Heras.

La juerga desarrolla un suceso contenido en Los olvidados ${ }^{14}$, novela que trata sobre la formación de un barrio suburbano en las afueras de Madrid y las condiciones de miseria en las que viven sus habitantes, en su mayor parte emigrantes procedentes de las regiones más desfavorecidas de España. Con Los clarines del miedo Lera pretendía ofrecer una visión de las corridas de toros diferente, pues diferente era el concepto en el que él las tenía, a la hasta entonces divulgada por la literatura española y extranjera de tema taurino. ${ }^{15}$ De ahí que su novela la protagonicen no grandes figuras del toreo, sino matadores anónimos, que se juegan la vida en las improvisadas plazas de los míseros pueblos de España, con el único objetivo de sobrevivir. ${ }^{16}$

La juerga se halla, por tanto, vinculada a Los olvidados y a Los clarines del miedo, tanto temáticamente como en cuanto a objetivos. Por un lado, tematiza el mundo de las juergas flamencas, lo que la conecta con Los olvidados; por otro, recrea la marginalidad del mundo del flamenco, al igual que Los clarines del miedo recreaba la marginalidad del mundo de los toros. Pero, además, con La juerga Lera prosigue su análisis de los estratos sociales más bajos, lo que hubiera convertido a estas tres novelas, de haber sido publicada la que nos ocupa, en un "tríptico de la marginación".

En Los clarines del miedo no se produce una contraposición entre la fiesta de los toros como brillante espectáculo organizado y las tristes capeas de los pueblos, al menos no de forma explícita. Contrariamente, el eje sobre el que se articula la trama de La juerga es precisamente la oposición "cante grande", es decir, cante jondo, y "flamenquería". La novela reivindica el cante jondo, de carácter minoritario, por ser la expresión más genuina del arte de los gitanos, frente al flamenco más popular, variante superficial y degradada del verdadero cante.

Dividida en tres partes claramente diferenciadas, en la primera (Capítulos 1 a 7), que se desarrolla en Madrid, los personajes principales aparecen desarraigados de su entorno

11 MINISTERIO DE CULTURA, Archivo General de la Administración, Caja: (3)50/21/13171, Expediente: 941 61. Todas las citas de la novela contenidas en este trabajo proceden de este original.

${ }_{12}$ Agradecemos a Adelaida de Lera Menés, hija de nuestro autor, el préstamo del original en su poder, así como también de otros documentos de gran interés para nuestra investigación.

13 BNE, Arch. AML/21/4 La juerga.

${ }^{14}$ Se trata del episodio de los músicos ciegos que amenizaban las juergas que se corrían los clientes del prostíbulo granadino en el que trabajaba uno de los personajes femeninos de la novela, Martina. Véase LERA, Ángel María de (1957, primera edición), Los olvidados, Madrid Aguilar, pp. 197-203.

15 BNE, Arch. AML/37/6 Notas biográficas.

${ }^{16}$ En este sentido, la dedicatoria de la novela habla por sí misma: "A los héroes del hambre y del miedo. Nadie los recuerda porque no alcanzaron un nombre. Muchos de ellos, sin embargo, dejaron su vida en las capeas, y, todos, su juventud” (LERA, Ángel María de (1958, primera edición), Los clarines del miedo, Barcelona, Destino). 
y dialécticamente enfrentados a los secundarios en torno al eje auténtico/espurio. Las dos secuencias que integran el Capítulo 8 actúan a modo de intermezzo y constituyen una verdadera inmersión en el tren nocturno que conduce a los protagonistas a su lugar de origen: Andalucía. El narrador recrea magistralmente el ambiente y a los pasajeros, ofreciendo al lector actual un pedazo auténtico de la vida de aquellos tiempos. La segunda parte de la novela (Capítulos 9 a 20) tiene lugar en Andalucía, cuna del flamenco. Además de describir la pobreza y atraso de la región (p. 159, pp. 197-198, p. 256), el narrador presenta al lector el mundo de los gitanos (Capítulo 13), primitivos cultivadores del arte flamenco. Sus gentes, las cuevas en las que habitan, sus legendarias costumbres son descritas con el mismo respeto que preside las relaciones existentes entre gitanos y payos. Al entendimiento entre ambos contribuye una misma manera — casi religiosa — de concebir el cante.

El protagonista indiscutible de la novela es José Luna Martínez, "Bocanegra", pero no tanto él en cuanto personaje, sino por lo que representa. Envuelto en un halo mítico, venerado por quienes lo conocen, marcado por el fatalismo, como tantos otros personajes lerianos, es el superviviente último de una manera de concebir e interpretar el cante, cuya pureza amenaza con desaparecer con la muerte del anciano. Sus acompañantes - "Risueño" y "Pelusa" - comparten esta visión con él. No así su hija, Cayetana, para quien el viaje a Andalucía constituirá una vuelta a los orígenes, un reencuentro con su perdida identidad, así como también la reconciliciación con el padre, que, tras asegurarse la continuidad de su arte, podrá morir en paz.

Curro Marchena y "Niño Carmona" son personajes caracterizados como superficiales. Hacen gala de un patético narcisismo, que se revela, por ejemplo, en su desproporcionada reacción ante los abucheos de "Bocanegra" (p. 62). Su única función en el relato parece ser la de servir de contrapunto a "Bocanegra", Cayetana, "Pelusa" y "Risueño".

En cuanto a los gitanos, el narrador elude su confrontación con los payos. En este sentido, las palabras de Torcuato el Mirlo resultan toda una declaración de intenciones: "nos tenemos que echar poco en cara gitanos y payos" (p. 275). Los calés aparecen caracterizados como grupo:

Los hombres escupian a veces el polvo, pero sin moverse apenas. Estaban como amodorrados bajo el sol, aspirándolo por todos los poros del cuerpo. Eran hombres cenceños, de rizos lustrosos, de largas patillas, casi todos con rastros de viruela y todos con aire jarifo. El que no descalzo, en alpargatas. Las chaquetillas, con las mangas cortas. Las cinturas, apretadas bajo la faja negra de siete vueltas. Ensombrerados sin excepción. No hablaban. Tampoco dormían realmente ni descansaban. Veían simplemente pasar el tiempo, que se venía y se iba con el sol (p. 244).

Solo Torcuato el Mirlo es individualizado por el narrador como hombre alto y extraordinariamente fornido. Frente a descripciones neutras, como la anteriormente citada, hay que mencionar la "gitanofobia" del dueño de la posada, "Tejeringuero", que desconfía siempre de los calés (pp. 178-179, p. 219).

En el mundo en el que se desarrolla la acción prima una concepción de la hombría que se define por la brutalidad. En cuanto a cómo han de proceder los hombres con las muje- 
res, "Risueño" sostiene: "hay que darles primero mucho capote para ir recogiéndolas poco a poco y luego poder liárselas uno a la cintura" (p. 17). De ahí que la violencia contra ellas fuera algo ante lo que nadie se sorprendía, ni la mujer misma (p. 14).

Pese a lo dicho, Lera apunta en esta novela temas que adquirirán pleno desarrollo en obras posteriores: la fortaleza y valentía de las mujeres de campo o la homosexualidad. Y, así, el personaje de Candelas prefigura el de Noemí (Tierra para morir, 1964). Su presencia en la novela resulta altamente subversiva: no solo no actúa como se esperaba que hiciera una mujer "decente" en la época, sino que, además, con su actitud — "provocativa"— y sus palabras cuestiona de raíz, como harán otros personajes femeninos lerianos, el opresivo rol impuesto a la mujer por el Franquismo:

[Candelas a Cayetana] ;No le arriendo las ganancias a ninguna de mis amigas que se han casado! Apañar ropa sudada y vieja, lavar, fregotear y parir. ;Esa es la vida de cualquier casada de mi clase! Y andar toda la vida de luto, cuando no por un familiar tuyo, por un pariente de él, o por un hijo. Y si te quedas viuda, ya ves: a pedir por las casas. Si yo me hubiera casado, a la edad que tengo, ya parecería una vieja. iPara vestir santos mejor, hija! (pp. 324-325).

El tema de la homosexualidad, aquí apenas insinuado, lo desarrollará nuestro autor, años después, en Trampa (1962). La aparición de "los jovenzuelos amanerados" (p. 58), que hacían "alarde de un exagerado acento andaluz" (p. 53) y cuyos nombres son "Zafiro", "Maravilla" y "Palillos" en el Capítulo 3, sirve para insinuar el carácter homosexual de la relación existente entre Curro Marchena y "Niño Carmona". Tanto el narrador como sus personajes, haciéndose eco de la homofobia imperante en la época, se refieren a ellos con términos como "maricas" (p. 5), "jovencitos de pitiminí" (p. 65) o "mariconcetes" (p. 86).

A través del personaje del señor Vilanova, el narrador incorpora una tercera perspectiva con respecto al flamenco: la de aquellos que lo aborrecen por identificarlo con atraso e incultura:

Es una señal de atraso y de falta de cultura. Es una cosa de gitanería. Y mientras a los españoles nos dé por eso, no seremos nada. La prueba está en que cuanta más flamenquería hay en una región, más miseria y más suciedad también [...]. ;Menos jipíos, menos castañuelas y más cultura! ¿Cuántos analfabetos hay en Andalucía? ¿Cuántos hay en Cataluña? Por cada uno que haya en mi tierra, aquí, diez, por lo menos... ¿Y cuántas fábricas hay en Cataluña? ¿Cuántas en Andalucía? Por cada una de aquí, hay veinte allá. Y eso es lo que vale hoy, eso es lo que vale (p. 261).

Por su manera de expresarse el señor Vilanova recuerda a don Juan, médico de Los clarines del miedo (1958), que argumenta de forma similar, pero contra los toros. Ambos caracteres se hacen eco del antiflamenquismo de autores muy leídos por Lera, como, por ejemplo, los de la Generación del $98 .{ }^{17}$ Del señor Vilanova se sirve también el narrador para

${ }^{17}$ El señor Vilanova, no obstante, cambia de opinión tras la función: "Creía que todo esto era muy diferente. Pero ahora..." (p. 296). 
reflejar una realidad — la diversidad de las diferentes regiones de España— que por aquellas fechas interesaba ocultar al Régimen.

En cuanto a las técnicas narrativas, hemos de decir que en La juerga Lera trata de atenuar, como ya hiciera en Los clarines del miedo, las evidencias de la omnisciencia del narrador. Y, así, por ejemplo, encontramos "tímidos" mecanismos de distanciamiento como el uso de "sin duda" ("Le pareció, sin duda, un delirio insensato", p. 81) o "quién sabe si" ("Ambas quedaron pensativas, quién sabe si recorriendo con la imaginación una serie de recuerdo [sic] grabados en la memoria", p. 332).

Por otro lado, son los personajes mismos quienes relatan sus propias historias o las historias de otros entes de ficción, y no el narrador. De este procedimiento hemos encontrado numerosos ejemplos: la misteriosa historia de Cayetana es puesta en boca del guitarrista "Cartagenero" y su cantaor (p. 7); "Bocanegra" cuenta, a petición de "Risueño", cómo aprendió a cantar la seguidilla, en un largo parlamento en primera persona (pp. 13-15); $\mathrm{Cu}$ rro Marchena y "Niño Carmona" narran, en apretada síntesis, sus orígenes (pp. 90 y 94, respectivamente); Pepe, el "Tejeringuero", rememora su propia historia hablando con su hija (p. 185).

La espectacular reducción del número de retrospecciones es también una muestra inequívoca de los esfuerzos realizados por Lera para despojar al narrador de parte de su poder y aproximarse así a los postulados del objetivismo en boga. Por ello estos "saltos atrás" son mucho más breves que en Los olvidados y Los clarines del miedo y no afectan a los protagonistas, sino a personajes secundarios como "Tejeringuero" (Cap. 11, pp. 204-207 y Cap. 13, pp. 237-239) o incluso a caracteres que ni tan siquiera aparecen directamente en la narración, sino a través de las historias relatadas por otros - apuñalamiento de Antonio el Tomate, "rey de los gitanos de la serranía" (pp. 164-165)—.

Hemos registrado varios ejemplos de monólogo interior, que aparece siempre entre paréntesis. El primero de ellos, muy breve (p. 209), reproduce los pensamientos de "Risueño". El resto (pp. 211-213) supone una inmersión en la conciencia de Cayetana. Técnica que nuestro autor había introducido en Los clarines del miedo, significa, según José María Castellet, "el más rotundo paso hacia la total desaparición de la figura del autor", al tiempo que "aporta a la literatura de nuestros días la dimensión más profunda y compleja del hombre: su propia subjetividad". ${ }^{18}$

Pero si hay un procedimiento en La juerga que destaca sobre los demás es la anticipación. El narrador anuncia una y otra vez la muerte de "Bocanegra". En el Capítulo 2 es el propio personaje quien expresa sus deseos de morir en su tierra (p. 86). La firma del contrato con la compañía de "Niño Carmona" en la primera parte de la novela supone el principio del fin — la muerte espiritual— del anciano cantaor:

Aquel hombre había impreso una extraña solemnidad, dentro de una expectación dramática, a un hecho tan simple como estampar una firma al pie de un contrato, como si se tratara de

${ }^{18}$ CASTELLET, José María (1957), La hora del lector, Barcelona, Seix Barral, pp. 32 y 33, respectivamente. 
un compromiso inexorable, decisivo para su vida. Y así era, en efecto. Y todos lo sabían. Era el acto de un vencido que firmaba su propia capitulación sin condiciones. Por eso la pluma quedó temblando todavía en la mano grande de abultadas venas azules (p. 96).

También los acompañantes del señor Pepe presienten el trágico final. "Risueño" compara el tabladillo en el que va a actuar "Bocanegra" con un patíbulo; "Pelusa" siente "repelucos" (p. 228); Cayetana se preocupa repetidamente por la salud de su padre, al que encuentra pálido (pp. 207-208), agotado (p. 302) y envejecido (p. 209). Hasta el narrador se pronuncia acerca del decaimiento del personaje (p. 265). Los presagios se intensifican hacia el final, en una progresión in crescendo (p. 297, p. 304, pp. 309-310, p. 320) que culmina con la anunciada muerte del protagonista (p. 322). El efecto está, en nuestra opinión, muy logrado. No solo contribuye a intensificar la intriga, sino también la catarsis final.

Siguiendo los postulados del objetivismo y actuando a modo de cámara fotográfica, el narrador reproduce con gran acierto algunas de las conversaciones de los personajes (p. 53, p. 102, p. 120). Con el objeto de conferirles mayor verosimilitud, imita algunas de las características propias de la lengua de los caracteres: el uso de "y" en lugar de "ll" - "chiquiyo", "biyetes", "degoyao"- o la utilización de palabras de origen gitano como "chavea", "fetén", "gachó", "parné” o "pinrel".

A diferencia de Los olvidados y Los clarines del miedo, novelas en las que el humor está completamente ausente, en La juerga hemos detectado algún que otro caso de ironía, tanto por parte del narrador (p. 21) como de alguno de los personajes (p. 30). La comicidad, si bien en grado muy limitado, está también presente en la novela (p. 220, p. 248).

Las sensuales descripciones del paisaje (p. 161) o la atribución de rasgos humanos a objetos inanimados son elementos que nuestro autor introduce en sus primeras novelas y se convertirán, con el paso de los años, en señas de identidad de su estilo. En La juerga destacan las personificaciones de la guitarra. Y, así, ora gemía, dolorida (p. 5), ora su voz, "igual que la de una mujer, acariciaba, huía y tornaba, llena de promesas y de risas, como un cascabeleo traído y llevado por el viento" (p. 33). "Risueño" llama "Carmeliya" a la suya. Según el tocaor, "es mi 'quería' para siempre y no me falla nunca" (p. 32). De ahí que, cuando decide quedarse solo, al final de la novela, la apriete patéticamente contra su pecho (p. 362). ${ }^{19}$

Otra característica que asoma en La juerga y que posteriormente definirá el estilo de nuestro autor es su lograda ambientación. La presencia del sereno (p. 78), el gaseosero de la estación de tren (p. 142) o el pregonero (p. 273), el sonido de la radio a la hora del parte (p. 204) o los chisqueros de mecha con los que los personajes encienden sus cigarrillos (p. 136) retrotraen al lector a épocas que tal vez ni siquiera llegó a conocer, pero que estas referencias evocan con gran fuerza.

${ }^{19}$ El narrador personifica también el coche de Carmona (p. 25, p. 109), en una descripción que anticipa la del automóvil de Álvaro (Trampa, 1962), o el teatro (p. 100, p. 118, p. 126). 


\section{ANÁLISIS DE LA JUERGA [1957, 1961] A LA LUZ DE SU EXPEDIENTE DE CENSURA}

Pese a los años transcurridos desde su publicación, Censura y creación literaria en España (1939-1976), de Manuel L. Abellán ${ }^{20}$ sigue constituyendo punto de referencia insoslayable para el estudio de la censura franquista en la producción cultural española de posguerra. En los años ochenta aparecieron también La censura: Función política y ordenamiento jurídico bajo el franquismo (1936-1975), de Román Gubern, especializado en cine, y La censura de Prensa durante el franquismo (1936-1951), de Justino Sinova, sobre el impacto de la censura en las publicaciones periódicas. ${ }^{21}$ Desde entonces hasta la fecha el estudio de la censura franquista ha experimentado un considerable desarrollo y se ha visto enriquecido por las contribuciones de los propios protagonistas — agentes y sujetos pacientes de la actividad censorial, esto es, responsables de los órganos de censura y escritores-, que han plasmado sus experiencias tanto en obras de investigación como de carácter memorialísti$\mathrm{co}^{22} \mathrm{El}$ análisis de las estrategias utilizadas por los escritores para atenuar los efectos del temido lápiz rojo del censor — lo que se ha dado en llamar el "discurso de la censura" ——23, los

20 ABELLÁN, Manuel L. (1980), Censura y creación literaria en España (1939-1976), Barcelona, Ediciones Península.

21 GUBERN, Román (1981), La censura: Función política y ordenamiento jurídico bajo el franquismo (1936-1975), Barcelona, Ediciones Península; SINOVA, Justino (1989), La censura de Prensa durante el franquismo (1936-1951), Madrid, Espasa Calpe.

${ }_{22}$ Del lado de los agentes pueden consultarse los trabajos de antiguos directores generales de Cultura Popular como Juan Beneyto Pérez o Miguel Cruz Hernández (BENEYTO PÉREZ, Juan (1987), "La censura literaria en los primeros años del franquismo. Las normas y los hombres", en ABELLÁN, Manuel L., Diálogos Hispánicos de Amsterdam. Censura y literaturas peninsulares, $N^{\circ}$ 5, Amsterdam, Rodopi, pp. 27-40; CRUZ HERNÁNDEZ, Miguel (1987), "Del deterioro al desmantelamiento: los últimos años de la censura de libros", en ABELLÁN, Manuel L., Diálogos Hispánicos de Amsterdam. Censura y literaturas peninsulares, $\mathrm{N}^{\circ}$ 5, Amsterdam, Rodopi, pp. 41-56). Del de los escritores, las obras colectivas de Antonio Beneyto (BENEYTO, Antonio (1977), Censura y política en los escritores españoles, Barcelona, Plaza y Janés) o Sergio Vilar (VILAR, Sergio (1964), Manifiesto sobre Arte y Libertad. Encuesta entre los intelectuales y artistas españoles, Barcelona, Editorial Fontanella). De gran interés resultan también las muchas y muy interesantes noticias vertidas por José Luis Cano en Los cuadernos de Velintonia o Carlos Barral y José Manuel Caballero Bonald en sus memorias (CANO, José Luis (1986), Cuadernos de Velintonia, Barcelona, Seix Barral; BARRAL, Carlos (2001), Memorias, Barcelona, Península; CABALLERO BONALD, José Manuel (2001), La costumbre de vivir. La novela de la memoria, Madrid, Alfaguara). Juan Goytisolo, por último, ha relatado extensamente y con no poca ironía sus experiencias con la censura en algunos de los artículos recogidos en El furgón de cola (GOYTISOLO, Juan (2001), El furgón de cola, Barcelona, Seix Barral).

${ }_{23}$ CHAMPEAU, Geneviéve (1988), "Decir callando", Mélanges de la Casa de Velázquez, XXIV, pp. $277-$ 295; SÁNCHEZ REBOREDO, José (1988), Palabras tachadas. (Retórica contra censura), Alicante, Instituto de Estudios "Juan Gil-Albert", Excma. Diputación Provincial; CHAMPEAU, Geneviéve (1991), "Censure, morale et écriture à l'époque du réalisme social", Mélanges de la Casa de Velázquez, XXVII, 3, pp. 139-161; NEUSCHÄFER, Hans Jörg (1994), Adiós a la España eterna. La dialéctica de la censura. Novela, teatro y cine bajo el franquismo, Barcelona, Anthropos. 
estudios de $\operatorname{casos}^{24} \mathrm{o}$ la investigación histórica propiamente dicha ${ }^{25}$ son otras tantas vertientes desde las cuales los investigadores tratan de arrojar luz sobre la enmarañada y opaca historia de la censura franquista. Contamos, además, con los fondos del Archivo General de la Administración (AGA), en Alcalá de Henares, valiosa e inagotable fuente de información, abiertos al público desde hace ya varias décadas.

En este apartado analizaremos el expediente de censura de La juerga y el original contenido en él con el objeto de formular hipótesis con respecto a las razones por las que la novela quedó inédita.

Lera presenta La juerga a censura en 1961, es decir, en un momento en el que todavía regía, pese a haber sido promulgada en plena Guerra Civil y con carácter provisional, la primera ley de censura de la Dictadura - la Ley de Prensa e Imprenta de 22 de abril de 1938 - Esta norma que, en un principio, había afectado solo a la prensa y a la radio, poco después se haría extensiva al resto de medios de comunicación y al mundo del $\operatorname{libro}^{26}$ y no sería sustituida por una nueva ley hasta $1966 .{ }^{27}$

Por ello los escritores que durante el Franquismo desearan publicar en España debían someter sus obras a "consulta previa". No obstante, no podían hacerlo directamente, sino a través de su editor. Ello quiere decir que antes de presentar el manuscrito, habían de contar con una editorial que se comprometiera a realizar todos los trámites en su nombre. Este primer paso suponía ya un importante obstáculo para los escritores considerados "desafectos".

Si bien durante los primeros años el ejercicio de la censura había recaído en diferentes instituciones ${ }^{28}$, en 1951 se centralizó en un único ministerio, creado a tal efecto, el MIT (Ministerio de Información y Turismo), que fue presidido por Gabriel Arias Salgado, católico integrista, hasta $1962 .{ }^{29}$

${ }^{24}$ En este ámbito destacan los numerosos trabajos sobre diversos autores de Lucía Montejo Gurruchaga, así como también el de Paula Martínez-Michel en torno a la controvertida y castigada figura de Alfonso Sastre (MARTÍNEZ-MICHEL, Paula (2003), Censura y represión intelectual en la España franquista: El caso de Alfonso Sastre, Hondarribia, Editorial Hiru).

25 Véase Eduardo Ruiz Bautista (RUIZ BAUTISTA, Eduardo (2005), Los señores del libro: propagandistas, censores y bibliotecarios en el primer franquismo, Gijón, Trea o RUIZ BAUTISTA, Eduardo (2008), Tiempo de censura. La represión editorial durante el franquismo, Gijón, Trea). Ha de tenerse también en cuenta la importante labor llevada a cabo desde 2006 por la revista digital Represura. Revista de Historia Contemporánea Española en torno a la represión y la censura aplicadas al libro, codirigida por José Andrés de Blas y Fernando Larraz y publicada por la Universidad de Alcalá de Henares (www.represura.es).

${ }^{26}$ Para ello fueron de vital importancia la Orden de 29 de abril de 1938 y la de 15 de julio de 1939.

27 Nos referimos a la Ley de Prensa e Imprenta de 15 de marzo de 1966, llamada también Ley Fraga.

${ }_{28}$ Comisión de Cultura y Enseñanza (1936), Delegación de Estado para Prensa y Propaganda (1937), Ministerio de Educación Nacional y Servicio Nacional de Prensa y Propaganda (1938), Vicesecretaría de Educación Popular (1941) y Subsecretaría de Educación Popular (1945).

${ }^{29}$ Gabriel Arias Salgado (1904-1962): Vicesecretario de Educación Popular y Delegado Nacional de Prensa y Propaganda de Falange Española Tradicionalista y de las JONS desde 1941 hasta 1946; Ministro de Información y Turismo desde 1951 hasta 1962. Sobre Gabriel Arias Salgado véase VADILLO LÓPEZ, Diego (2011), "Gabriel Arias Salgado o el integrismo censor", Represura. Revista de Historia Contemporánea Española en torno a la represión y la censura aplicadas al libro, $\mathrm{N}^{\circ} 7$ (www.represura.es). 
Lo primero que llama la atención con respecto a La juerga es que pese a haberla compuesto Lera en 1957, no la presente a "consulta previa" hasta 1961. De lo relatado por Rodríguez de las Heras se desprende que esto pudo deberse a los desacuerdos habidos entre autor y editor y al consiguiente retraso en la firma del contrato. ${ }^{30}$ Esta teoría quedaría avalada por el hecho de que Lera publica su primera novela, Los olvidados (1957), en Aguilar, pero no Los clarines del miedo (1958) ni La boda (1959), que aparecen en Destino. La colaboración con Aguilar la retoma nuestro autor en 1960, año en el que ve la luz Bochorno.

Sea como fuere, en 1961 Lera anunciaba, en entrevista a José Ramón Marra-López, la publicación de La juerga y glosaba su contenido de la siguiente manera:

En este año saldrá La juerga, a la que estoy dando los últimos toques. Es una novela que describe ese paisaje del alma española confuso, nebuloso y mal interpretado casi siempre que es el cante jondo. ${ }^{31}$

Pero lo cierto es que la novela nunca vio la luz ni en España, por las razones que a continuación examinaremos, ni en ningún otro país, pese a que Lera intentó publicarla tanto en Francia como en Alemania. En Francia, a través de la mediación de Juan Goytisolo que, a la sazón, trabajaba para Éditions Gallimard..$^{32}$ En Alemania fue el propio escritor quien ofreció la novela a Hoffmann und Campe, editorial que había traducido al alemán y publicado Los clarines del miedo (Fanfaren der Angst) en 1960 y haría lo propio con Bochorno (Glühender Mai) en 1961 y La boda (Spanische Heirat) en $1963 .{ }^{33}$

\subsection{Los originales}

Un cotejo de los tres originales existentes de La juerga revela que el que se halla en poder de los herederos de Lera es, si no idéntico, muy similar al conservado en el AGA. ${ }^{34}$

${ }^{30}$ RODRÍGUEZ DE LAS HERAS, Antonio, op. cit., p. 95.

31 MARRA-LÓPEZ, José Ramón (1961), “Diálogo con Ángel M. a de Lera”, Ínsula, 171, p. 4.

32 BNE, Arch. AML/38/24 GOYTISOLO, Juan.

33 Véase documento en el Anexo: Carta de 22 de julio de 1960 de Lera a Hoffmann und Campe (UNTERNEHMENSARCHIV / GANSKE VERLAGSGRUPPE, Hamburg, “Autorenmappe 1"). En el archivo de la editorial hamburguesa, además de esta carta, se conservan dos informes sobre La juerga: de 21 de mayo de 1961 el primero (UNTERNEHMENSARCHIV / GANSKE VERLAGSGRUPPE, Hamburg, “Autorenmappe 2: Gutachten") y de 30 de junio de 1961 el segundo (UNTERNEHMENSARCHIV / GANSKE VERLAGSGRUPPE, Hamburg, "Autorenmappe 2: Gutachten"), reproducidos ambos en el Anexo a esta investigación. Agradecemos a la editorial Hoffmann und Campe y particularmente a su amable archivera, Andrea Lesemann, que en el verano de 2016 nos abriera sus puertas y pusiera a nuestra disposición todos los documentos relacionados con Lera contenidos en su archivo.

${ }^{34}$ Gracias al original en poder de los herederos, sabemos que de los dos títulos que Lera barajaba para la obra prefería Bronce. Nuestro escritor había publicado un fragmento de la novela en 1959 - el único que ha visto la luz hasta la fecha- en el homenaje que la revista Punta Europa dedicó a José María Millás Vallicrosa, Catedrático de Lengua y Literatura hebreas de la Universidad de Barcelona. 
Por lo que respecta a este último, hay que decir que tiene una extensión de 362 páginas y, además de tachaduras en rojo y en azul, presenta anotaciones y correcciones de diverso tipo, presumiblemente hechas tanto por el autor como por el censor. Las anotaciones afectan a cuestiones tipográficas; las correcciones, a la ortografía: uso de comillas y puntos suspensivos o utilización de "y" en lugar de "ll" para reproducir el yeísmo propio de la lengua andaluza. En las galeradas del texto aparecen también páginas sobre las que se han pegado trozos de papel con párrafos que resulta imposible contrastar con los escritos originalmente. Así, por ejemplo, en la p. 355 se adivina que Lera pudo haber utilizado este recurso para corregir lo indicado por el censor. La numeración de las páginas no siempre es precisa, como tampoco lo es el número de capítulos. ${ }^{35}$

El original conservado en el Archivo de Ángel María de Lera, en la BNE, presenta un aspecto considerablemente distinto: el texto ha reducido su volumen a 276 páginas; va precedido por unos versos de Manuel Machado que actúan a modo de epígrafe ${ }^{36}$; aparece impoluto, sin corrección alguna; y presenta una estructura clara, en veinte capítulos numerados en romanos.

La existencia de los tres originales y su diferente grado de elaboración nos lleva a aventurar la hipótesis de que el guardado en el AGA y el conservado por los herederos sean primeras versiones de la obra, que Lera, teniendo en cuenta las "indicaciones" del censor, trató de rehacer. El texto de la BNE sería el resultado de este proceso.

\subsection{El informe ${ }^{37}$}

El 14 de febrero de 1961 Aguilar solicita autorización para la publicación de La juerga. A la obra se le asigna número de expediente —el 941-61—, como era lo habitual, y se encarga de su lectura a un censor. ${ }^{38}$

\footnotetext{
${ }^{35}$ La numeración de los capítulos es doble —en arábigos y romanos—, pero no coincidente: en arábigos la obra tendría 20 capítulos; en romanos, XV.

${ }^{36}$ La cita aparece dos veces, en dos páginas distintas, escrita a mano, primero, y después, mecanografiada. Reza: "A todos nos has cantado / en una noche de juerga / coplas que nos han matado".

${ }^{37}$ En el Anexo reproducimos el informe contenido en el expediente de censura de La juerga.

38 "En las obras de teatro podían intervenir más de diez censores, en las películas más de veinte, mientras que de las novelas solían ocuparse uno o dos" (NEUSCHÄFER, Hans-Jörg, op. cit., p. 50).
} 
El análisis del expediente de La juerga revela que fue leída por un solo censor -Pala$\operatorname{cios}^{39}$ - , que no se escudó tras el anonimato, como era lo habitual ${ }^{40}$, y firmó de forma perfectamente legible el siguiente informe, que reproducimos literalmente: ${ }^{41}$

Novela de costumbres andaluzas ceñida, por su argumento, a la pintura realista del cante jondo, que va paseando por colmaos y poblachos una alucinada compañía de bohemios, en la que no podía faltar la inquietante hembra cantaora (Cayetana) y alguna otra con la que la farándula topa en su continuo rodar por los mesones [ilegible] y es, ¿justamente? [no se lee bien], en el dibujo de estos tipos femeninos donde se cargan las tintas de sensualidad y de lascivia que se ven tachadas por el lápiz rojo. Todo lo demás [subrayado en rojo] AUTORIZABLE [subrayado en rojo]

Sólo las no tachadas arriba en lápiz azul. [Ilegible]-II-61

Madrid, 17 de febrero de 1961

El Lector,

Firma

Palacios

La última línea del informe: "Sólo las no tachadas arriba en lápiz azul" se refiere a la relación de tachaduras que aparece en el mismo documento como respuesta a la pregunta “¿Ataca a la moral?”, relación de difícil interpretación, ya que el censor tacha y vuelve a tachar y produce una lista muy confusa. No obstante, la relación aparece dos veces más: en la solicitud de autorización y en la carta que el MIT remite a Aguilar el 23 de febrero de 1961 comunicando a la editorial la resolución final:

Suprimase [sic] lo señalado en las páginas 34-138-139-216-217-226-230-350 en lápiz azul [errata: rojo]. Presentese [sic] nuevas galeradas impresas.

\footnotetext{
${ }^{39}$ No aparece en la lista de censores proporcionada por Manuel L. Abellán en Censura y creación literaria en España (1939-1976), op. cit., pp. 305-313; tampoco en la de Paula Martínez-Michel, op. cit., pp. 45-47. Justino Sinova recoge el nombre de Alfonso Palacio, pero aparte de la discrepancia en el apellido, no parece que se trate de la misma persona, ya que, según Sinova, Alfonso Palacio "firmaba parte de incidencias de Censura de Revistas en 1943-44" (SINOVA, Justino, op. cit., p. 295).

${ }^{40}$ La identidad de los censores es, en la mayor parte de los casos, desconocida. Eran designados a través de un número y, si firmaban los informes, generalmente lo hacían de forma ilegible. No obstante, existen listas parciales de censores, como las elaboradas por Abellán, Sinova o Martínez-Michel (véase nota 39). Según Lucía Montejo Gurruchaga, "la presencia de mujeres en el órgano censor era escasísima. Las primeras firmas de mujeres en los expedientes no se encuentran hasta los años sesenta" (MONTEJO GURRUCHAGA, Lucía (2004), "Efectos de la censura en la obra de Blas de Otero. Recursos de enunciación", Ancia. Revista de la Fundación Blas de Otero, Año II, Nº, 3, p. 32, nota 3).

${ }^{41}$ El informe aparece escrito a mano, en tinta de color verde. Resulta difícil de leer, por la mala caligrafía del censor, así como también porque se halla repleto de tachaduras.
} 


\subsection{Análisis de las tachaduras}

De las siete tachaduras en rojo que el censor exige hacer a Lera seis son de carácter sexual y bastante pacato, por cierto. Se trata de breves textos en los que se describe el deseo sexual en términos no muy diferentes a los que ilustra la que a continuación reproducimos:

Al acercarse y al moverse con tanto aire llegó hasta los hombres un crudo olor a lecho matrimonial revuelto y sudado.

Los ojos de los hombres la recorrieron en todos los sentidos, deteniéndose morosamente en el abultado pecho, de carne mullida y temblorosa. El descote dejaba ver sobre los hombros las hendiduras de las cintillas del sostén... (p. 34).

Lera no elimina ninguna de estas tachaduras en el original de la BNE, todas reaparecen intactas (AGA: p. 34-BNE: pp. 27-28; AGA: pp. 216-217-BNE: pp. 166-167; AGA: p. 226BNE: p. 173; AGA: p. 230-BNE: p. 176; AGA: p. 350-BNE: p. 267).

La séptima tachadura, la contenida en las pp. 138-139, se refiere a la Guardia Civil:

—Oye: ¿no es ese guardia el que dicen Rebollo, aquel que estuvimos convidando en Alcá$z a r ?$

-Claro que sí, hombre. ;El gachó se puso como el Quico! Y eso que al principio no quería.

- Pues me ha mirado, pero no ha querido reconocerme.

-Natural. Esos no conocen ni a su padre cuando van de servicio. Por eso dicen que tener un amigo guardia civil es como tener un duro falso (pp. 138-139).

Pese a no cuestionar la autoridad de la "Benemérita", el comentario negativo acerca de los agentes fue suficiente para que el lápiz rojo del censor actuara. No obstante, tampoco en este caso Lera se plegó a los requerimientos de la institución censoria: el fragmento aparece intacto en la p. 110 del original de la BNE.

Una atenta lectura del texto conservado en el AGA revela otras muchas tachaduras, realizadas tanto en rojo como en azul, tachaduras sobre las que Lera trabajó, como pone de manifiesto el cotejo de los diferentes originales.

La mayor parte de estas supresiones tienen relación con el cante jondo y, particularmente, con el concepto de la "pena negra" ${ }^{42}$; un número mucho más reducido, con Cataluña. Veamos algunos ejemplos.

Al intentar explicarle a su hija lo que es la pena, "Bocanegra" sostiene:

Va uno hablando y nadie le contesta. No ve uno más que sombras. Son el padre, la madre, una mujer, el amigo... Se van. Y uno, siempre solo. El avariento, el rico, el poderoso..., itrat

\footnotetext{
${ }^{42}$ Los personajes, particularmente "Bocanegra", se hacen eco de las ideas contenidas en la conferencia de Lorca sobre el cante jondo (GARCÍA LORCA, Federico (1997), "Arquitectura del cante jondo", Obras completas III. Prosa, Barcelona, Galaxia Gutenberg, pp. 33-52). Se aprecian también reminiscencias lorquianas en el relato del apuñalamiento de "Tomate" (pp. 164-165) y el monólogo interior de "Risueño" (p. 209).
} 
qué? Al remate, todos nos encontramos igual. ¿Para qué correr, para qué afanarse tanto? Siempreentrares an punato de

Prosigue:

En Madrid y en otras ciudades, los hombres se engañan para no pensar. No tienen tiempo para sentir. Es como si estavieran borrachos todo el dia y luego, por la noche, se emborrachan de otra manera. iQuieren vivir! iPobreticos! Aquí, la gente tiene que vivir... No es que quiera morir. Es otra cosa: tiene que vivir... ;La pena! Por eso, cuando se siente de verdad, se queda uno tranquilo y a gusto, porque lo sabe uno todo... (p. 201).

En estos casos Lera sí siguió las indicaciones del censor, eliminando la primera tachadura y reescribiendo la segunda de la siguiente manera (BNE: p. 154):

Yo he visto mucho, he vivido mucho, he conocido a gentes famosas — siguió diciendo el viejo-, ¿y qué? Joselito era joven, tenía mucho dinero, le querían todas las mujeres. Como él, otros muchos. Por éso [sic] tiene uno que gritar lo que siente. Y nada como el cante para eso. $Y$ en ningún sitio como aquí.

Los pasajes en los que los personajes intentan definir la pena aparecen también tachados —p. 10, pp. 41-42, p. 357—. ¿Tal vez porque quienes llegan a sentirla, conscientes de su triste e inexorable destino, caen en la más profunda de las abulias (tachaduras de las pp. 156, 186 o 356)? El fatalismo de los personajes no era el espejo en el que deseaba mirarse la autocomplacencia del Régimen. El narrador pone el dedo en la llaga en un pasaje que no fue censurado:

Sobre aquellos seres angustiados aleteaba la pena negra, la sin redención, la de la vida inexplicable y sin esperanza... Ellos escuchaban, sumisos, la propia condena, con la satisfacción dolorosa de sentirse víctimas inocentes. La rota voz del "Bocanegra" era su propia voz y los propios gemidos; y su agonía, la que ellos estaban viviendo (pp. 297-298).

"Bocanegra" se duele de que el "verdadero cante" esté muriendo. Al Franquismo, desde luego, no le interesaba, sobre todo teniendo en cuenta el potencial subversivo de algunas coplas..$^{43}$ De ahí que potenciara el folklore — "lo barato", según "Bocanegra"—, llegando a convertirlo en tópica seña de identidad y reclamo para turistas. De nada le valió a Lera utilizar como aval del cante a don Fidel, el cura. ${ }^{44}$

Este folklore "barato", según la concepción del viejo "Bocanegra", correspondería a lo que Manuel Vázquez Montalbán ha denominado canción nacional o nacionalista: "andalucista en la imaginería, la melodía y la pronunciación, vinculada a una España agrícola

43 “¿Pa qué trabajas, minero, / con tantísima fatiga, / si los que tienen dinero / no han bajao nunca a una mina?" (p. 291).

44 Don Fidel ama el cante. Lo justifica y lo explica en las pp. 285-286; 292-293; 294-295. 
y provinciana"45 la canción nacional "testimonia un voluntarismo ideológico determinado: efectismo, nacionalismo, majeza". ${ }^{46} \mathrm{Su}$ momento de mayor eclosión tiene lugar durante el período autárquico (1939-1954). De ahí que constituya una síntesis de todo lo considerado por el Régimen como peculiar español: "individualismo (en oposición al colectivismo y comunitarismo marxista), peculiaridades raciales [...], exaltación del destino histórico, excelencias de todo lo nuestro (mujeres, vino y música)" ${ }^{47}$ La canción nacional cuenta entre sus letristas más inspirados con Antonio Quintero, Valerio y Rafael de León, "herederos subculturales" ${ }^{48}$ de los poetas del $27 .{ }^{49}$ Para su popularización el Régimen se valió de la radio, "instrumento uniformador e ideológico de primera necesidad". ${ }^{0}$ Algunos de sus más conocidos intérpretes fueron Manolo Escobar, Conchita Piquer o Peret.

Por otro lado, la marginalidad del mundo del flamenco, provocada por la miseria, no era algo que al Régimen le agradara mostrar. De ahí tachaduras como la de la p. 151:

["Risueño" a "Pelusa"]: Mira: casarse es algo distinto a lo que tú piensas. Hay que ser de otro modo. Hay que llevar otra vida. [...] to que no puede pasar es un hombre que vive como nosotros, de noche, a satto de mata, entre juerga y juerga. A no ser que la mitur sea como noso= tros. En ese caso, si. Pero para eso no hace faltacasarse...

- Pero uno no puede dejar esto. ¿Quté putede hacer uno ya sino cantar y bailar? Yo me he eriado, como tú sabes, en los "colmaos" como aquel que dice. Nací en un barrio donde todo el mundo se bailaba o se cantaba algo y creo que mi madre me echó sabiendo yo un poco de las tos cosas. $Y$, como en mi casa no nos ponan de comer, cata cual turo que apañarse como butenamente putdo. Y, asi, desde chavea, aprendí a buscámetas, yendo solito de mesa en mesa por tos cafés, cantando coptas o batitando por to que querian darme. Numea fut a la esenta, ni me hizo falta para ganarme los "gabis". Mientras los demás chiquillos de mi edad no tenían una gorda, a mi no me faltaba una peseta. Total: que me arregosté en esa vida... Yo creo que me paś, poe más o menos, lo que a todos nosotros. Inome vengas diciendo que esto es una des= gracia. A míne gusta...

El "Pelusa" terminó con un gesto de labios y manos, que subrayaban su fatalismo y su des= dén.

En el texto de la BNE Lera eliminó también este fragmento.

Las tachaduras relacionadas con Cataluña resultan más "inocentes” y también más absurdas: la primera constituye una breve referencia a la sardana (AGA: p. 261; BNE: p. 200); en la segunda el señor Vilanova despotrica contra el flamenco (AGA: pp. 263-264; BNE: p. 200); la última censura la frase “¡Visca Catalunya!” (AGA: p. 313; BNE: p. 237).

45 VÁZQUEZ MONTALBÁN, Manuel (2000), Cancionero general del franquismo 1939-1975, Barcelona, Crítica, p. XV.

${ }^{46}$ Ibídem, p. XVI.

${ }^{47}$ Ibídem, p. XIX.

${ }^{48}$ Ibídem, p. XIX.

${ }^{49}$ Los poetas del 27, especialmente García Lorca y Alberti, se interesaron por la lírica tradicional y reivindicaron con fervor — recuérdense los ya citados trabajos de Lorca- el cante jondo. También lo habían hecho algunos autores del 98, como Manuel Machado, cuyos versos sirven de epígrafe a La juerga.

${ }^{50}$ VÁZQUEZ MONTALBÁN, Manuel, op. cit., p. XIV. 
El "Una, Grande y Libre" no casaba con la diversidad lingüística y cultural de España. De ellas Lera solo suprime la última; las dos anteriores permanecen intactas.

¿Por qué La juerga quedó inédita? En nuestra opinión, porque Lera no se plegó —al menos no completamente- a los requerimientos de la institución censoria y no hizo las supresiones exigidas, supresiones que no solo afectan a pasajes de carácter sexual — tachaduras en rojo-, como en un primer momento pudiera parecer, sino a otros muchos - tachaduras de color azul — que, de haber sido eliminados, hubieran desvirtuado completamente el sentido de la obra.

En las "Notas biográficas" conservadas en el Archivo de Ángel María de Lera ${ }^{51}$ nuestro autor se refiere a La juerga en los siguientes términos:

En Mayo próximo, aparecerá mi quinta novela, cuyo [cortado] JUERGA', que, siguiendo, la línea de 'LOS CLARINES DEL MI[cortado] aborda el problema de la pena y del cante jondo [cortado] vulgarmente 'cante flamenco'.

Estas declaraciones, pese a su brevedad, confirman dos de nuestras hipótesis:

1. Que Lera no renunció voluntariamente a publicar La juerga, como sostiene Gayle C. Wehr. ${ }^{52}$ De hecho, él esperaba una resolución positiva por parte del MIT, como ponen de manifiesto no solo estas declaraciones, sino también las anteriormente citadas, hechas en entrevista a Marra-López en 1961.

2. Que con La juerga el objetivo que nuestro autor perseguía era tratar el tema del cante jondo. De ahí que, dado que las tachaduras realizadas por el censor en color azul afectaban precisamente a los pasajes en los que se trataba de definir el concepto de la pena, lo más probable es que Lera rehusara publicar la novela en tales condiciones. $^{53}$

La cronología de las primeras obras publicadas de Lera - una al año- refuerza nuestro argumento: Los olvidados (1957), Los clarines del miedo (1958), La boda (1959), Bochorno (1960) y Trampa (1962). De haber autorizado el MIT La juerga ocuparía el quinto lugar, es decir, el hueco existente entre Bochorno y Trampa.

Por otro lado, el contenido crítico de la novela es muy alto. Se revela, desde el primer momento, en la elección de los personajes que protagonizan la trama y los ambientes en los que se desarrollan sus vidas, pero adquiere mayor intensidad a medida que el tren en el que viajan "Bocanegra", Cayetana, "Pelusa" y "Risueño" se adentra en las profundidades de Andalucía. La descripción de los pasajeros que suben y bajan o del abandono en el que se hallan los pueblos que el viajero puede contemplar desde la ventanilla revelan la existencia

51 BNE, Arch. AML/37/6 Notas biográficas.

52 WEHR, Gayle C., op. cit., p. 3.

53 Ángel Carlos de Lera, hijo del autor, supone que su padre no encontró editor (Ángel Carlos de Lera, en carta de 11 de septiembre de 2012 a la autora). El expediente de censura conservado en el AGA muestra que esto no fue así. 
de una España "negra”, pobre y atrasada. Los personajes, en sus conversaciones, descubren algunos de los problemas que los afligen: trenes en los que han de viajar de pie, escasez de trabajo, pobreza, miseria... La crítica está, en nuestra opinión, muy lograda, ya que emana de lo descrito, lo que refuerza su eficacia.

La práctica censoria ejercida sobre La juerga confirma la rigidez del período Arias Salgado, pero matizaría la hipótesis de Abellán según la cual se habría tratado de una etapa caracterizada por:

la ausencia total de conflictos: pocas tachaduras, escasas denegaciones y prácticamente modificaciones insignificantes pone de manifiesto que la severidad censoria fue durante el período de Arias-Salgado una política sin ambigüedades, pero con previo aviso, y que, por tanto, ningún escritor se atrevió a ir más allá de lo que explícitamente estaba demarcado. ${ }^{54}$

Y llama la atención sobre el hecho de que fueron los editores y sus consejeros de lectura quienes "asumieron la ingrata o fascinante tarea de enderezar manuscritos demasiado imprudentes". ${ }^{55}$ También Ángel Carlos de Lera sospecha que Aguilar pudo tener algo que ver en la práctica censoria efectuada sobre las obras de su padre. ${ }^{56}$

No deja de sorprender todo ello en cualquier circunstancia, pero sobre todo teniendo en cuenta que, cuando Lera presenta el manuscrito de La juerga a censura, corría el año 1961, momento en el que la efervescencia crítica alcanzaba en España puntos hasta entonces nunca conocidos. Sobre esta paradoja ha llamado la atención Román Gubern:

Es interesante observar que en contraste con la modernización de la economía durante este período, se produjo en cambio un estancamiento de la censura y de las restricciones a la libertad de información y expresión. ${ }^{57}$

Por último, el hecho de que esta novela quedara inédita supone una mutilación en el conjunto de la obra de Lera, que pierde, así, coherencia. Lera afirmaba establecer su producción por ciclos: rural, urbano y de la emigración para sus obras anteriores a 1967. En el ciclo rural incluía Los clarines del miedo (1958) y La boda (1959); en el urbano, Los olvidados (1957), Bochorno (1960) y Trampa (1962), y en el de novelas de la emigración laboral, Hemos perdido el sol (1963) y Tierra para morir (1964). ${ }^{58}$ Además, en tanto que novelista español, nuestro autor se había impuesto como misión "recrear los tipos, las costumbres y los paisajes de mi país. Sobre todo, traducir el sentido trágico que de la vida tenemos los españoles". ${ }^{59}$ En este sentido, resulta perfectamente plausible la hipótesis de que

54 ABELLÁN, Manuel L., op. cit., p. 151.

55 Ibídem.

56 Ángel Carlos de Lera sostiene: "Si se coge la obra de mi padre en su conjunto, el hecho de que ejerciera la censura sobre sus obras la presión que ejerció nos lleva al trasfondo de la cuestión y a su cambio de casa editorial. Los tentáculos del Sistema franquista llegaban a todas partes y nadie —o casi nadie — quería tener problemas con la dichosa Censura" (en carta de 11 de septiembre de 2012 a la autora).

57 GUBERN, Román, op. cit., p. 123.

58 CASTELO, Santiago (22-08-1974), “Conversación con Angel María de Lera”, ABC (Sevilla), p. 11.

59 BNE, Arch. AML/37/6 Notas biográficas. 
Los clarines del miedo y La juerga constituyeran, en cuanto a su concepción, un díptico, sobre todo si aceptamos como fecha de composición de La juerga el año 1957.

Pero el daño producido por la acción de la censura sobre La juerga no solo afecta a la obra misma o al plan por ciclos que Lera se había trazado, sino también al estudio de los personajes y las técnicas narrativas de la totalidad de la producción leriana: al de los personajes por cuanto existe una "continuidad" entre ellos entre novela y novela; al de las técnicas narrativas, porque en la obra que nos ocupa nuestro autor "corrige" algunos de los errores cometidos anteriormente mientras que se afianza en el uso de procedimientos más logrados.

De este modo la oscura e innombrable censura franquista, a menudo arbitraria y omnipresente - dentro y fuera de la mente de los escritores - siempre, interfería de forma inapelable en el destino de La juerga, inédita aún en la actualidad, y en la trayectoria de Ángel María de Lera.

\section{BIBLIOGRAFÍA CITADA}

Abellán, Manuel L. (1980), Censura y creación literaria en España (1939-1976), Barcelona, Ediciones Península

Barral, Carlos (2001), Memorias, Barcelona, Península

Beneyto, Antonio (1977), Censura y política en los escritores españoles, Barcelona, Plaza y Janés

Beneyto Pérez, JuAn (1987), "La censura literaria en los primeros años del franquismo. Las normas y los hombres", en Abellán, Manuel L., Diálogos Hispánicos de Amsterdam. Censura y literaturas peninsulares, $\mathrm{N}^{\circ} 5$, pp. 27-40

Bne, Arch. AmL/1-38. Período que abarca: 1935-1984

BNE, Arch. AmL/21/4 La juerga (original inédito)

BNE, Arch. AmL/37/6 Notas biográficas

Bne, Arch. Aml/38/24 Goytisolo, Juan (carta)

Caballero Bonald, José Manuel (2001), La costumbre de vivir. La novela de la memoria, Madrid, Alfaguara

Cano, José Luis (1986), Cuadernos de Velintonia, Barcelona, Seix Barral

Castelo, Santiago (22-08-1974), “Conversación con Angel María de Lera”, ABC (Sevilla), p. 11

Castellet, José María (1957), La hora del lector, Barcelona, Seix Barral

Castro Díez, Asunción (ed.) (2004), Los olvidados, de Ángel María de Lera, Madrid, Castalia

Champeau, Geneviéve (1988), "Decir callando", Mélanges de la Casa de Velázquez, XXIV, pp. 277295

Champeau, Geneviéve (1991), "Censure, morale et écriture à l'époque du réalisme social”, Mélanges de la Casa de Velázquez, XXVII, 3, pp. 139-161

Cruz Hernández, Miguel (1987), "Del deterioro al desmantelamiento: los últimos años de la censura de libros", en Abellán, Manuel L., Diálogos Hispánicos de Amsterdam. Censura y literaturas peninsulares, $\mathrm{N}^{\circ} 5$, pp. 41-56

Escolar Bareño, Luis (1966), Prólogo a Novelas, de Ángel María de Lera, Madrid, Aguilar

García de Nora, Eugenio (1970²), La novela española contemporánea (1939-1967), Tomo III, Madrid, Gredos

García Lorca, Federico (1997), "Arquitectura del cante jondo", Obras completas III. Prosa, Barcelona, Galaxia Gutenberg, pp. 33-52 
Goytisolo, JuAn (2001), El furgón de cola, Barcelona, Seix Barral

Gubern, Román (1981), La censura. Función política y ordenamiento jurídico bajo el franquismo (1936-1975), Barcelona, Ediciones Península

Hatton, Robert W. (ed.) (1971), Los clarines del miedo, de Ángel María de Lera, Waltham, Massachusetts, Ginn and Company

Hernández, Ramón (1980), Prólogo a Los clarines del miedo, Madrid, Espasa-Calpe S. A.

Hernández, Ramón (1981), Angel María de Lera, Madrid, Ministerio de Cultura

La juerga (original inédito) en poder de Adelaida de Lera Menés

Leeder, Ellen Lismore (1978), El desarraigo en las novelas de Angel María de Lera, Miami, Ediciones Universal

Lera, Ángel María DE (1957, primera edición), Los olvidados, Madrid, Aguilar

Lera, Ángel María de (1958, primera edición), Los clarines del miedo, Barcelona, Destino

Lera Menés, Ángel Carlos De, Carta de 11 de septiembre de 2012 a la autora de esta investigación

Listerman, Mary Sue (1982), Angel María de Lera, Boston, Twayne Publishers

Marra-López, José Ramón (1961), "Diálogo con Ángel M. a de Lera”, Ínsula, 171, p. 4

Marra-López, José Ramón (1964), "Una novela de interés nacional”, Ínsula, 207, p. 5

Martínez-Michel, Paula (2003), Censura y represión intelectual en la España franquista: El caso de Alfonso Sastre, Hondarribia, Editorial Hiru

Ministerio de Cultura, Archivo General de la Administración, Caja: (3)50/21/13171, Expediente: 941 61, La juerga

Montejo Gurruchaga, Lucía (2004), "Efectos de la censura en la obra de Blas de Otero. Recursos de enunciación", Ancia. Revista de la Fundación Blas de Otero, Año II, № 3, pp. 15-34

NeUSChäFer, HANs-Jörg (1994), Adiós a la España eterna. La dialéctica de la censura. Novela, teatro $y$ cine bajo el franquismo, Barcelona, Anthropos

Represura. Revista de Historia Contemporánea Española en torno a la represión y la censura aplicadas al libro, codirigida por José Andrés de Blas y Fernando Larraz y publicada por la Universidad de Alcalá de Henares (www.represura.es)

Rodríguez de las Heras, Antonio (1971), Angel M. ${ }^{a}$ de Lera, Madrid, Epesa

Ruiz BAutista, EduARdo (2005), Los señores del libro: propagandistas, censores y bibliotecarios en el primer franquismo, Gijón, Trea

Ruiz Bautista, Eduardo (2008), Tiempo de censura. La represión editorial durante el franquismo, Gijón, Trea

SÁnchez Reboredo, José (1988), Palabras tachadas. (Retórica contra censura), Alicante, Instituto de Estudios "Juan Gil-Albert", Excma. Diputación Provincial

Sinova, Justino (1989), La censura de Prensa durante el franquismo (1936-1951), Madrid, Espasa-Calpe

Thomas, Owen Durant (1972), La vida y obras de Angel María de Lera, (University of Illinois), Michigan, University Microfilms International

Thomas, Owen Durant (1977), Angel María de Lera: the Mann and his Novel, (New York University), Michigan, University Microfilms International

Unternehmensarchiv Gamske Verlagsgruppe, Hamburg, Carta de 22 de julio de 1960 de Ángel María de Lera a la editorial Hoffmann und Campe, en "Autorenmappe 1"

Unternehmensarchiv Gamske Verlagsgruppe, Hamburg, Informe sobre La juerga, 21 de mayo de 1961, en "Autorenmappe 2: Gutachten"

Unternehmensarchiv Gamske VerlagsgrupPe, Hamburg, Informe sobre La juerga, 30 de junio de 1961, en "Autorenmappe 2: Gutachten"

Vadillo López, Diego (2011), "Gabriel Arias Salgado o el integrismo censor", Represura. Revista de Historia Contemporánea Española en torno a la represión y la censura aplicadas al libro, $\mathrm{N}^{\circ} 7$ 
(wWw.represura.es)

VázQuez Montalbán, Manuel (2000), Cancionero general del franquismo 1939-1975, Barcelona, Crítica

Vilar, Sergio (1964), Manifiesto sobre Arte y Libertad. Encuesta entre los intelectuales y artistas españoles, Barcelona, Editorial Fontanella

Wehr, Gayle C. (1974), La novelística de Angel María de Lera (The Florida State University), Michigan, Xerox University Microfilms 


\section{ANEXO}

\section{Informe contenido en el expediente de censura de La juerga [1957]. Fechado el 17 de febrero de 1961.}

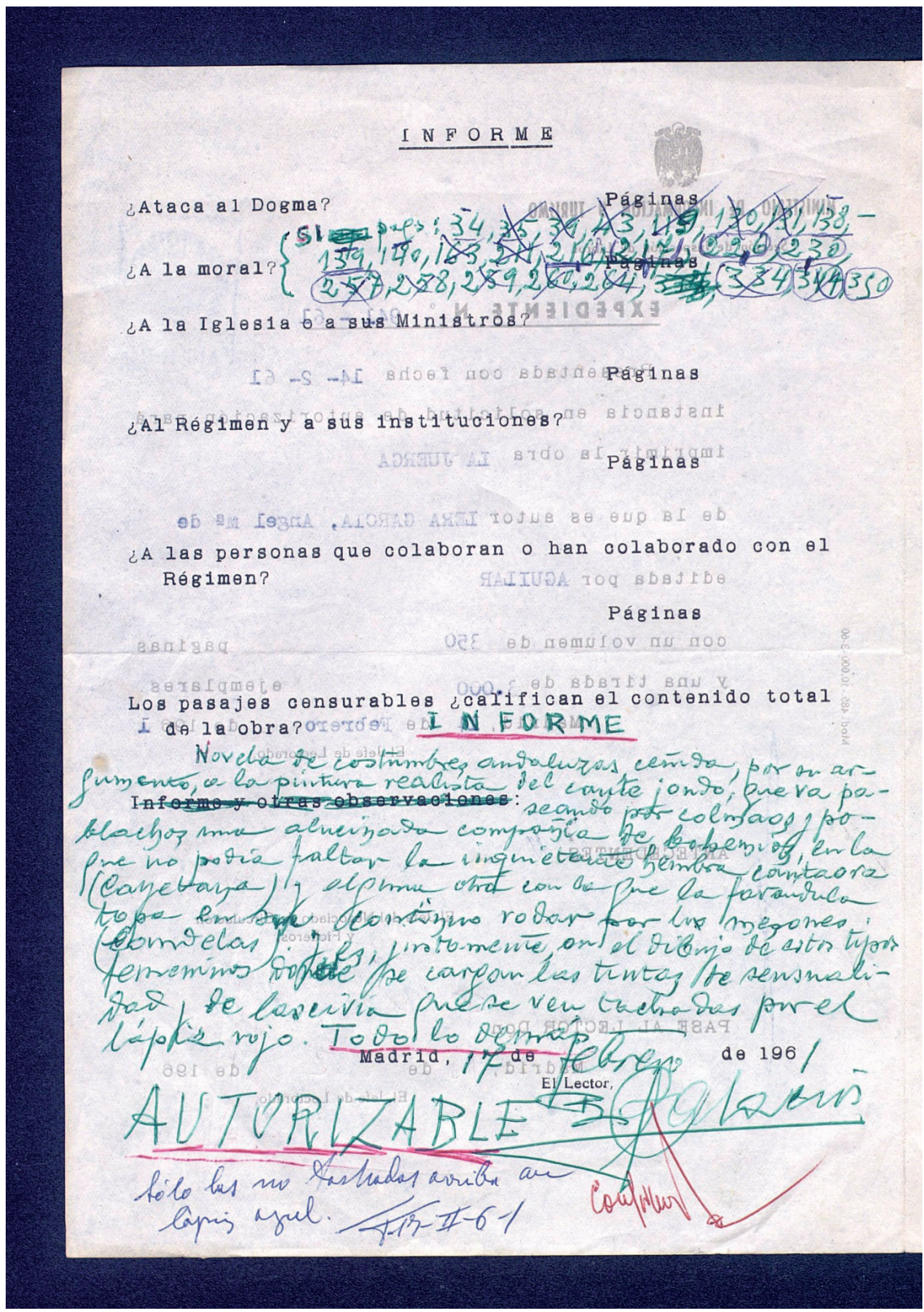




\section{Carta de Ángel María de Lera a la editorial hamburguesa Hoffmann und Campe anunciando el envío de Bronce (La juerga). Fechada el 22 de julio de 1960.}

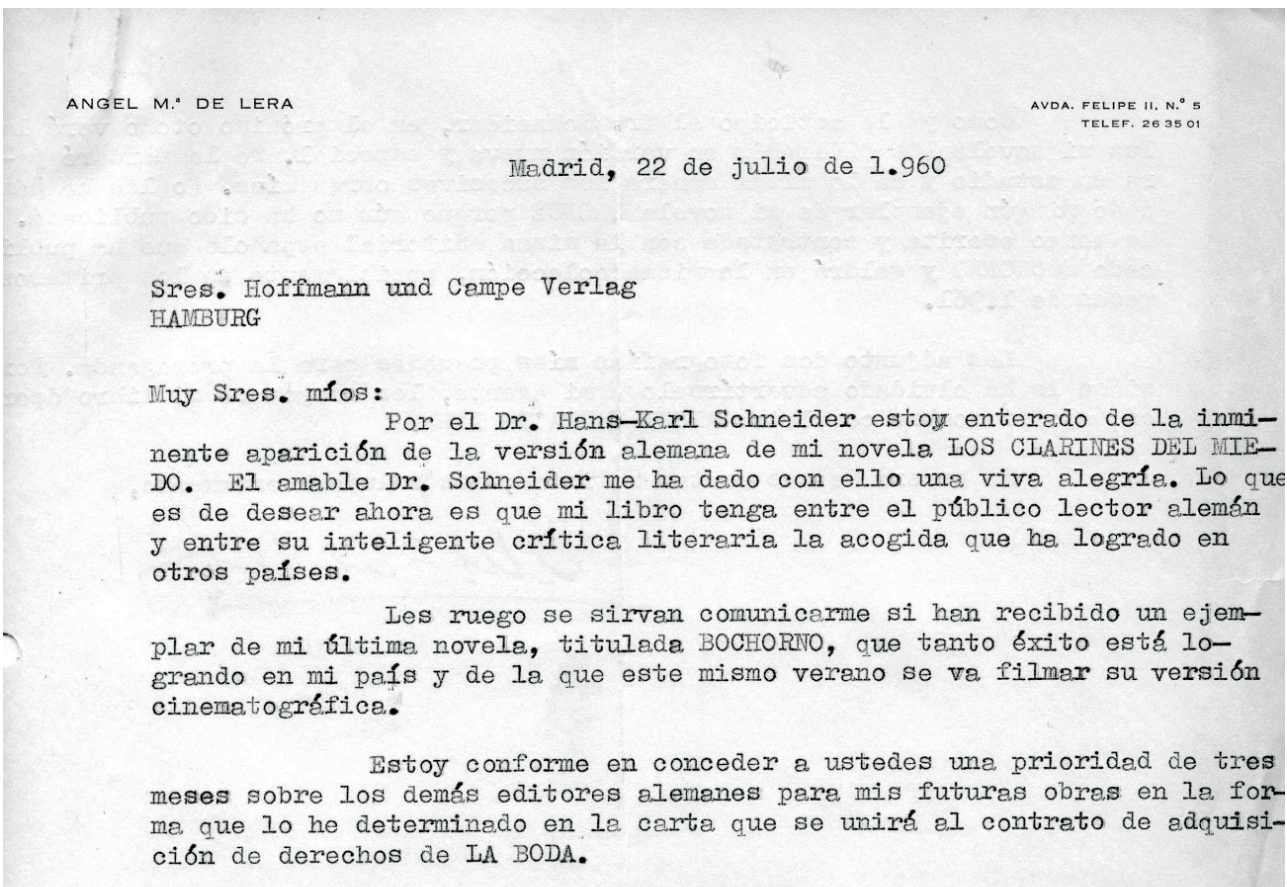

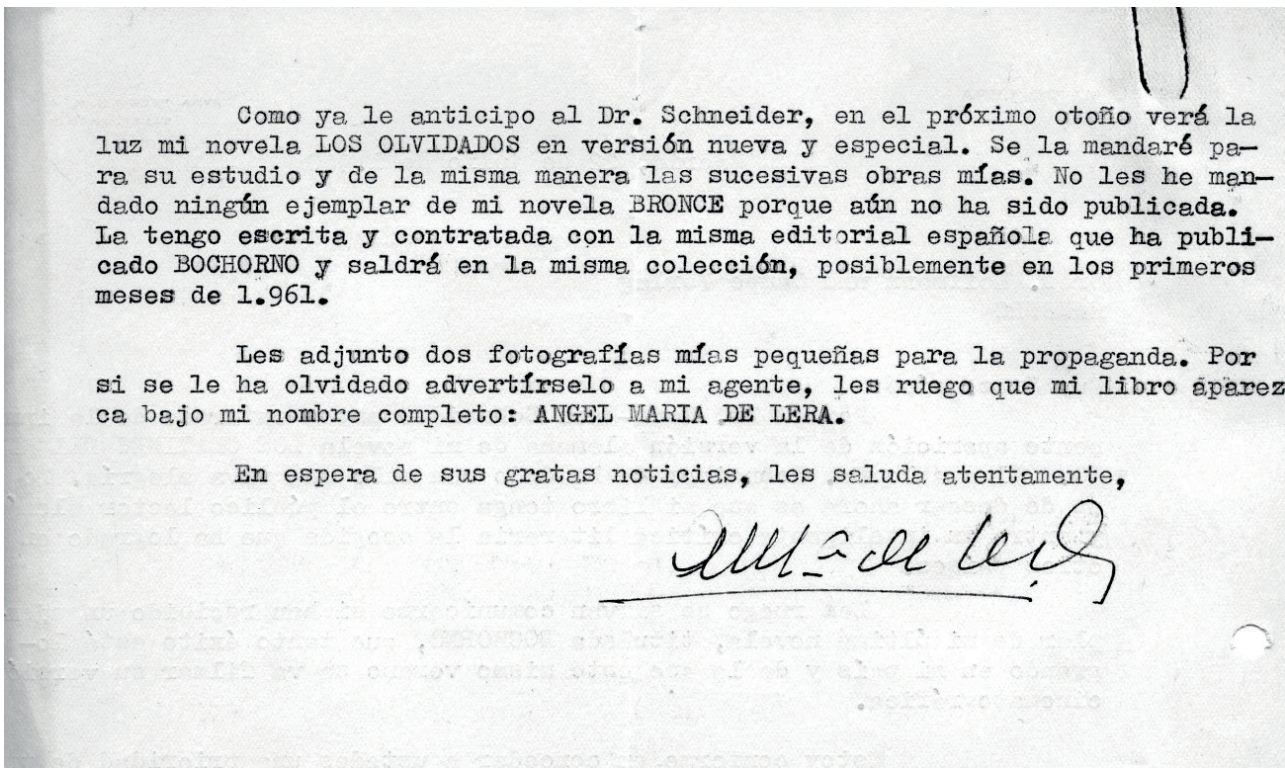




\section{Informes sobre La juerga de los lectores de Hoffmann und Campe:}

\subsection{De 21 de mayo de 1961. Firmado por el Dr. Schneider, traductor de Los clarines} del miedo (Fanfaren der Angst, 1960), Bochorno (Glühender Mai, 1961) y La boda (Spanische Heirat, 1963).

\subsection{De 30 de junio de 1961. Firma ilegible.}

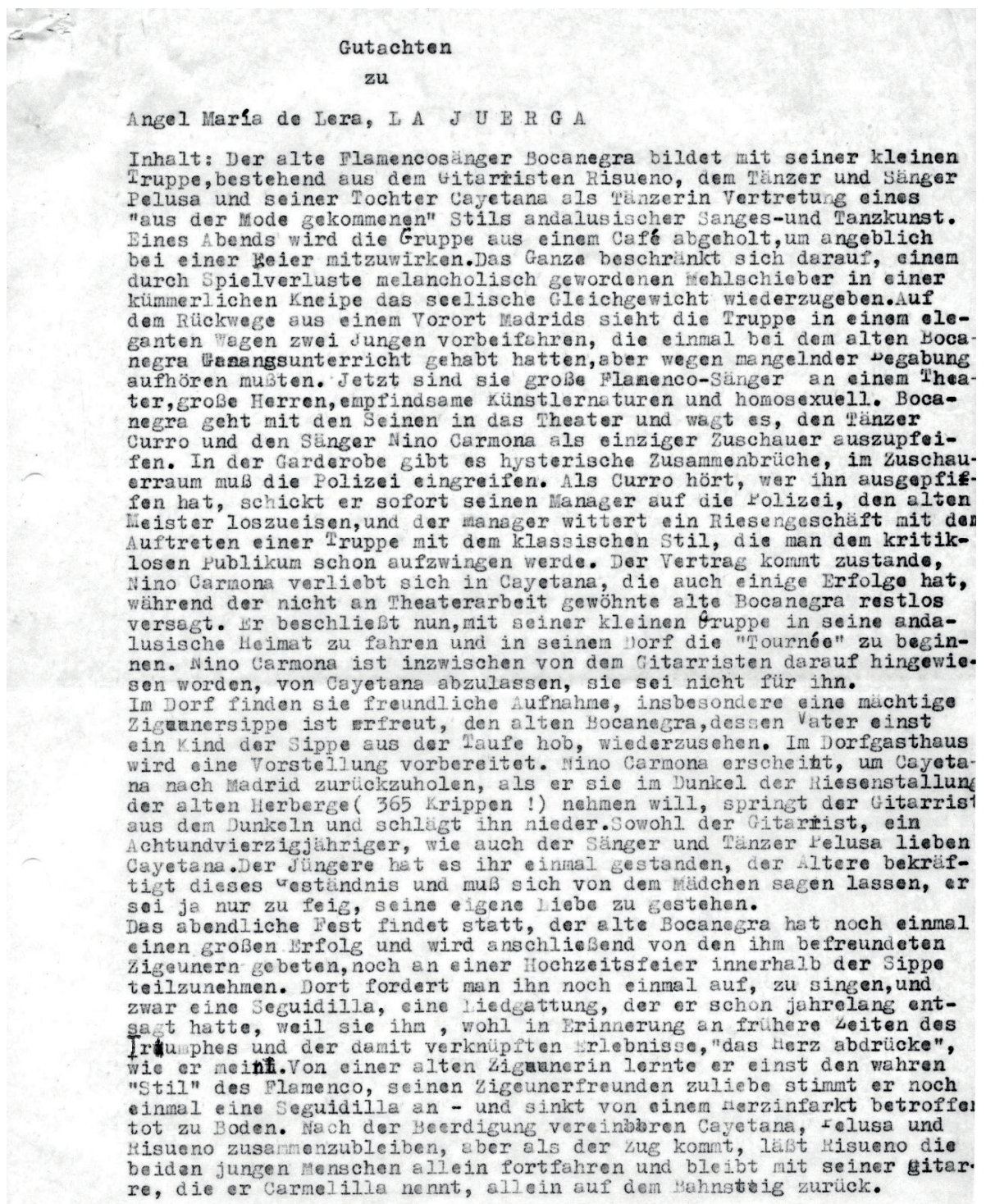




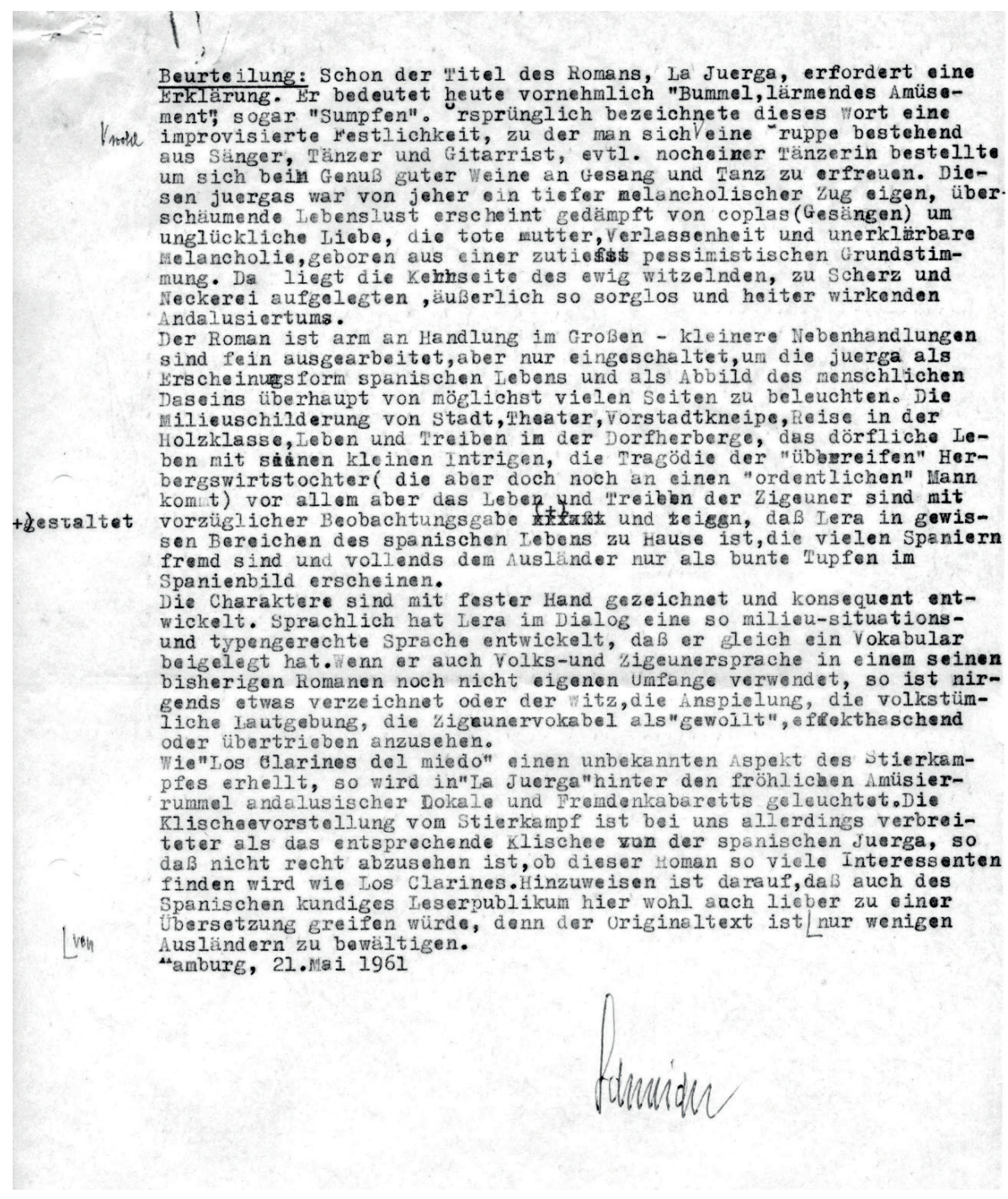




\section{1}

ANGEL MARIA DE I E R A : IA J U E R G A

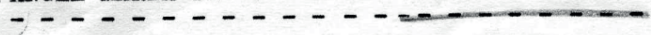

wanuskript, $276 \mathbf{s}$.

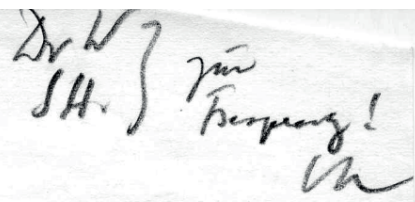

Der Verfasser will in diesem Roman eine innerspanische Erscheinung schildern: das Aussterben der echten andalusischen Volkskunst auf dem Gebiet des Gesangs ("cante jondo") und Tanzes und das Aufkommen einer folkloristischen Kunst, die für ein grösseres Publikum und für die Touristen berechnet ist und deren Vertreter Auslandstou"neen machen und in Madrider Theatern unter grosser Orchesterbegleitung auftreten. Hauptperson ist der alte Bocanegra, der seinerzeit der berühmteste Sänger Andalusiens war und der jetzt mit seiner Tochter Cayetana, dem Gitarrespieler El Risueño und dem jungen Tänzer El Pelusa in Maurid in Wirtschaften herumsitzt und darauf warten muss, dass irgendein vermögender Mann sich eine "noche de juerga" leisten will - ein in kleinerem Kreis veranstaltetes Fest, auf dem die Künstler singen und tanzen. Doch auch bei diesen Gelegenheiten werden die früher so verehrten und gefeierten Künstler schlecht behandelt. Bocanegra besucht nun mit seinem kleinen Kreis eine der neuen berühmten Veranstaltungen. Während das Publikum begeistert klatsøint, pfeift er empört. Es entsteht ein Tumult, Bocanegra kommt auf die Wache; aber als die beiden Künstler der grossen Truppe, Churro Marchena und Niño Carmona, erfahren, um wen es sich handelt, schicken sie sofort ihren Agenten zu Docanegra. Sie verehren ihn noch von früher her; ihr Agent muss gewissermassen eine Wiederentdeckung der alten Kunst in die Wege leiten und in einem Madrider Theater einen Abend für Bocanegra und seine Leute veranstelten. Dieser lässt sich wdderstrebend dazu überreden. Der Abend wird ein Fiasko, Bocanegras Stimme reicht für den grossen Raum nicht mehr aus. Das Publikum pfeift ihn aus, nur Cayetana gefällt den Leuten, obgleich sie - nach früheren Maßstäben gemessen - nur mittelmässig singt und tanzt. Bocanegra fährt nun mit seinen drei Getreuen in seinen Heimarort in Andalusien, steigt dort in einem alten Wirtshaus $a b$ und will eine Veranstaltung für die Dorfbewohner geben. In der ersten Nacht kommt Niño Carmona, der sich in 
$-2-$

Cayetana verliebt hat, in seinem Wagen, um sie zu entführen, muss aber unverrichteter Dinge wieder abgere abiehen. Sehr ausfuhrlich werden dann der andalusische Ort und seine Bewohner geschildert - zu den letzteren gehören auch viele Zigeuner, die hier in Höhlen leben und mit deren bedeutendsten Vertretern Bocanegra von Jugend auf befreundet ist. Der Abend findet statt, es wird ein unbeschreiblicher Triumph für Bocanegra und seine Kunst. Als er anschliessend in der Wohnhöhle eines Zigexuners zu Gast ist und dort eine Seguidilla singt, erliegt er einem Herzschlag. - Cayetana und ElPelusa fahren wieder nach Madrid; sie werden dort wohl zukünftig in Folklore-Veranstaltungen auftreten. Der Gitarrespieler El Risueño bleibt zurück, - er ist ein echter Vertreter der alten Kunst und kann sich nicht in die neue Zeit finden.

De Lera bat die Zusammehhänge und Verhältnisse mit sehr viel Iiebe und Sachkenntnis geschildert; allerdings lässt er sich durch seine innere Anteilnahme an dem Thema zuweilen verführen, seine Bịlder auf Kosten der Handlung etwas zu breit auszumalen. Er gerät nur selten - und dann auf recht interessante Weise - in ein gewisses Theoretisieren; im allgemeinen gelingt es ihm durch die ihm eigene Kunst der Charakterzeie zeichnung, seine Theorie in den Handlungen und Gesprächen der Personen zwanglos deutlich zu machen. Für meinen Geschmack ist der Tod Bocanegras (und damit der Tod der alten andalusischen Kunst) etwas zu stark symbolisch herausgestellt, und hier entbehrt die schilderung auch nicht einer gewissen Rührseligkeit. Für Spanier und Hispanisten ist dieses Buch eine reine Freude, - Jeser, denen das Thema etwas fremder ist, werden vielleicht nicht soviel Verständnis dafür aufbringen. Im Vergleich zu Leras letztem Roman "Bochorno", der allgemein interessante Probleme Spaniens behandelt, ist dieser vielleicht etwas speziell.

Hamburg, 30. VI. 61<smiles>[Mg]</smiles> 


\section{Traducción de los informes sobre La juerga de los lectores de Hoffmann und Campe. ${ }^{60}$}

\subsection{Valoración del primer lector}

Ya el título de la novela, La Juerga, requiere explicación. Particularmente hoy significa "correría", "divertimento ruidoso" o incluso "parranda". Originalmente esta palabra designaba una fiesta improvisada para la cual se pedía un grupo integrado por un cantaor, un bailaor y un guitarrista - y eventualmente otra bailaora - con el objeto de disfrutar del cante y del baile, saboreando un buen vino. Ya desde tiempos inmemoriales estas juergas se caracterizaban por su profunda melancolía: la rebosante alegría de vivir aparece apagada en coplas que, nacidas de una actitud profundamente pesimista ante la vida, se dedican al amor desgraciado, a la madre muerta, a la soledad y a una inexplicable melancolía. Ahí se encuentra el reverso del eterno bromear, expresado en chanzas y burlas, aparentemente tan despreocupado y alegre del andalucismo.

En general, la novela tiene poca acción: las pequeñas acciones secundarias están muy bien elaboradas, pero solo hacen su aparición para que se vislumbre, desde todas las perspectivas posibles, la juerga como forma de manifestación de la vida española y como reflejo de la existencia humana. El retrato costumbrista de la ciudad, del teatro, de la tasca suburbial, del viaje en tercera clase, del día a día en la posada, de la vida en el pueblo con sus pequeñas intrigas, de la tragedia de la ya muy madura hija del posadero, que, sin embargo, todavía consigue a un hombre "respetable" y, sobre todo, de la vida de los gitanos es diseñado con excelente capacidad de observación y muestra que Lera se siente en casa describiendo ciertas áreas de la vida española que les son ajenas a muchos españoles y que para los extranjeros solo aparecen como punto multicolor en la imagen de España.

Los caracteres son descritos con garra y consecuentemente desarrollados. Desde el punto de vista de la lengua, Lera desarrolla en el diálogo semejante diversidad de situaciones y tipos que crea un vocabulario propio. Aunque en ninguna de sus novelas anteriores había utilizado la lengua del pueblo y de los gitanos tan profusamente, no hierra en las descripciones, ni las bromas, las alusiones, el ambiente popular o los vocablos de los gitanos se perciben como "forzados", efectistas o exagerados.

Al igual que Los clarines del miedo ilumina un aspecto desconocido de la tauromaquia, así se da luz en La juerga a lo que hay detrás de los divertidos café-teatro andaluces, locales y extranjeros. El cliché del toreo está, no obstante, más extendido entre nosotros que el correspondiente a la juerga española, de modo que no es de prever que esta novela encuentre tantos interesados como Los clarines. Hay que indicar que el texto original presenta tantas dificultades que incluso el público lector alemán más avezado preferiría contar con una traducción.

\footnotetext{
${ }^{60}$ Los informes constan de dos partes: "Inhalt" (contenido) y "Beurteilung" (valoración). Solo hemos traducido la parte correspondiente a la valoración. Agradecemos a José Juan Ventura Usó, compañero y amigo, la revisión de los fragmentos traducidos.
} 


\subsection{Valoración del segundo lector}

De Lera describe las relaciones y circunstancias con gran detalle y conocimientos; no obstante, en ocasiones se deja llevar, a causa de su propio interés por el tema, y dibuja sus cuadros de forma demasiado extensa, a costa de la acción. Solo raras veces cae en una cierta teorización, pero entonces lo hace de manera verdaderamente interesante; en general, logra — gracias a su particular destreza para dibujar a los caracteres- explicar con claridad y soltura su teoría en las acciones y conversaciones de los personajes. Para mi gusto, la muerte de Bocanegra (y con ello la muerte del antiguo arte andaluz) es destacada simbólicamente de manera excesivamente fuerte. Y aquí la descripción tampoco prescinde de un cierto sentimentalismo. Para los españoles y los hispanistas este libro es una auténtica joya. Los lectores para quienes el tema resulte algo más desconocido quizá no lo comprendan muy bien. En comparación con la última novela de Lera, Bochorno, que en general trata interesantes problemas de España, ésta es tal vez un poco especial. 